\title{
Effects of Mixture Fraction on Edge-flame Propagation Speeds
}

\author{
Hang Song*, Philip Wang, Richard S. Boles, David Matinyan, \\ Hatsachai Prahanphap, Jesse Piotrowicz, Paul D. Ronney \\ Department of Aerospace and Mechanical Engineering \\ University of Southern California, Los Angeles, CA 90089-1453, USA \\ *Corresponding author; email: songhang@usc.edu
}

\section{Colloquium 4: Laminar flames}

\section{Word Count:}

\section{Total Length: $\underline{5680}$ words}

Main Text: 3095 words (calculated by Microsoft Word 2013)

Equations: 0 words

Nomenclature: 0 words

References: 437 words

- $\quad(23$ references +2$) \times(2.3$ lines $/$ reference $) \times(7.6$ words $/$ line $)=437$ words

Tables: 311.6 words

- Table1: (9 text lines +2 lines $) \times(7.6$ words $/$ line $) \times(2$ columns $)=167.2$ words

- Table2: $(17$ text lines +2 lines $) \times(7.6$ words $/$ line $) \times(1$ column $)=144.4$ words

Figures and Captions: 1836.4 words

- Fig 1: $(17 \mathrm{~mm}+10 \mathrm{~mm}) \times(2.2$ words $/ \mathrm{mm}) \times(1$ column $)+(35$ words in caption $)=94.4$ words

- Fig 2a: $(67 \mathrm{~mm}+10 \mathrm{~mm}) \times(2.2$ words $/ \mathrm{mm}) \times(1$ column $)+(18$ words in caption $)=187.4$ words

- Fig $2 \mathrm{~b}$ - Fig 1h: $(67 \mathrm{~mm}+10 \mathrm{~mm}) \mathrm{x}(2.2$ words $/ \mathrm{mm}) \mathrm{x}(1$ column $)+(0$ words in caption $)=169.4$ words

- Fig 3a: $(67 \mathrm{~mm}+10 \mathrm{~mm}) \times(2.2$ words $/ \mathrm{mm}) \times(1$ column $)+(30$ words in caption $)=199.4$ words

- Fig 3b: $(67 \mathrm{~mm}+10 \mathrm{~mm}) \mathrm{x}(2.2$ words $/ \mathrm{mm}) \mathrm{x}(1$ column $)+(0$ words in caption $)=169.4$ words

(C) 2016. This manuscript version is made available under the Elsevier user license http://www.elsevier.com/open-access/userlicense/1.0/ 


\begin{abstract}
The propagation speeds $\left(\mathrm{U}_{\text {edge}}\right)$ of nonpremixed edge-flames were measured as a function of stoichiometric mixture fraction $\left(Z_{\text {st }}\right)$ and global strain rate $(\sigma)$ for several fuel/oxidant/diluent combinations using a counterflow slot-jet burner. It was found that for fuel Lewis number $\left(\operatorname{Le}_{\mathrm{f}}\right) \approx 1$ and oxidant Lewis number $\left(\mathrm{Le}_{\mathrm{o}}\right) \approx 1$ with fixed $\sigma, \mathrm{U}_{\text {edge }}$ increases monotonically with increasing $\mathrm{Z}_{\text {st. }}$ In contrast, for $\mathrm{Le}_{\mathrm{f}}>1$ and $\mathrm{Le}_{\mathrm{o}} \approx 1$ with fixed $\sigma, \mathrm{U}_{\text {edge }}$ exhibits a minimum, typically at $\mathrm{Z}_{\mathrm{st}} \approx 0.3$, except for dimethyl ether which showed $\mathrm{U}_{\text {edge }}$ montonically decreasing with increasing $Z_{\text {st. }}$ These results indicate that $Z_{\text {st }}$ has both chemical and Lewis number effects on nonpremixed edge-flame speeds. For $\mathrm{Le}_{\mathrm{f}} \approx \mathrm{Le}_{\mathrm{o}} \approx 1$, chemical effects dominate over the whole range of $Z_{\mathrm{st}}$ whereas for $\mathrm{Le}_{\mathrm{fuel}}>1$ and $\mathrm{Le}_{\mathrm{O} 2} \approx 1$, Lewis number effects become important at low $Z_{\mathrm{st}}$. It is shown that all observed $U_{\text {edge }}$ vs. $Z_{\text {st }}$ trends are consistent with computed values of extinction strain rate $\left(\sigma_{\text {ext }}\right)$ of these mixtures in a $1 \mathrm{D}$ counterflow, thus $\sigma_{\text {ext }}$ serves as a simple surrogate for predicting edge-flame behavior.
\end{abstract}

Keywords: Edge-flame, Lewis number, mixture fraction, nonpremixed flames, counterflow 


\section{Introduction}

"Edge-flames" occur along the length of flame sheets where transitions from burning to non-burning conditions exist. Edge-flame behavior is used to interpret many types of non-uniform flame phenomena including flames in highly turbulent flows such as reciprocating-piston internal combustion engines where "holes" in flame sheets may open or re-seal, flames stabilized near a cold wall or splitter plate, or leading edges of flames spreading across condensed-phase fuel surfaces [1]. The most important property of an edge-flame is its propagation speed $\left(\mathrm{U}_{\text {edge }}\right)$, defined as the speed the edge moves relative to the unburned gases in the direction parallel to the flame sheet. Previous theoretical studies of edge-flames in premixed [24] and nonpremixed [5-9] configurations predict that edge-flames may propagate from the burning into the non-burning region, forming an "ignition front" with $\mathrm{U}_{\text {edge }}>0$ or retreat into the burned region, forming an “extinction front” with $\mathrm{U}_{\text {edge }}<0$. Many factors affect $\mathrm{U}_{\text {edge }}$ such as global strain rate $(\sigma)$, Lewis numbers (Le, ratio of mixture thermal diffusivity to reactant mass diffusivity) of fuel and oxidant, heat losses, and for nonpremixed edge-flames the stoichiometric mixture fraction $Z_{s t} \equiv 1 /\left(1+v X_{f} / X_{o}\right)$ where $v$ is the stoichiometric oxygen-to-fuel mass ratio and $\mathrm{X}_{\mathrm{f}}$ and $\mathrm{X}_{\mathrm{o}}$ are the mass fractions of fuel and oxygen in the unburned mixture streams.

While traditional nonpremixed combustion generally employs pure hydrocarbons mixing and burning with highly-diluted oxygen (specifically, air) resulting in low $Z_{\text {st }}$ (typically 0.06 ), new fuels and combustion technologies (biofuels, oxyfuel combustion, massive Exhaust Gas Recirculation, etc.) result much broader $\mathrm{Z}_{\text {st }}$ ranges - up to 0.8 for pure oxygen burning with highly-diluted fuel. In the widely-employed counterflow geometry, increasing $Z_{\text {st }}$ moves the flame location from the oxidizer side toward the fuel side of the stagnation plane, which results in significant differences in the reactant temperature/composition/time history. This was shown $[10,11]$ to cause very asymmetric flame properties with respect to $Z_{\text {st }}=0.5$ (where the flame resides at the stagnation plane) which was attributed [11] to shifts in $\mathrm{O}_{2}$ concentration profiles as $Z_{\text {st }}$ increases to coincide more closely with peak temperature locations, leading to increased radical production rates and thus more robust flames. No theoretical or computational study has examined $Z_{\mathrm{st}}$ 
effects on edge-flame properties. Prior nonpremixed edge-flame experiments [10] focused primarily on $Z_{\text {st }}=0.5$ with one data set taken at $Z_{\text {st }}=0.2$ and 0.8 for $\mathrm{CH}_{4} / \mathrm{N}_{2}-\mathrm{O}_{2} / \mathrm{N}_{2}$ mixtures for which Lewis numbers of fuel $\left(\mathrm{Le}_{\mathrm{f}}\right)$ and oxygen $\left(\mathrm{Le}_{\mathrm{o}}\right)$ are near unity. Studies of Le effects are relevant to systems employing fuels with very high or low molecular masses, resulting in widely varying Le $e_{f}$ which strongly affects $U_{\text {edge }}$ and extinction behavior [10] and, as will be shown, couple with $\mathrm{Z}_{\mathrm{st}}$ effects in unusual ways.

Accordingly, this work's objective is to study systematically $Z_{\text {st }}$ effects on edge-flame properties for varying $\sigma$ and varying Lewis numbers (by varying fuel and diluent type). Following prior work [10] a counterflow slot-jet (rather than round-jet) apparatus is employed because slot-jets provide extensional strain orthogonal to the slot plane yet little convection along the slot length, thus edge-flame propagation speeds in the laboratory frame are the propagation speed relative to the cold unburned gas far ahead of the edge-flame (or behind, for retreating edge-flames). This approach simplifies interpretation of experimental data.

\section{Experimental apparatus, procedures, scaling}

The counterflow slot-jet apparatus and procedures are similar those employed previously [10]. Thermal mass flow controllers regulated fuel and oxidizer jet exit velocities $\left(\mathrm{U}_{\mathrm{f}}, \mathrm{U}_{\mathrm{o}}\right)$ to obtain specified $\sigma=\left(\mathrm{U}_{\mathrm{o}}+\mathrm{U}_{\mathrm{f}}\right) / \mathrm{d}(\mathrm{d}=$ jet spacing, typically $7.5 \mathrm{~mm})$ and mixtures (fuel + diluent and $\mathrm{O}_{2}+$ diluent $)$ at the required $\mathrm{X}_{\mathrm{o}}$ and $\mathrm{X}_{\mathrm{f}}$ to obtain specified $\mathrm{Z}_{\mathrm{st}}$. Honeycomb inserts at the jet exits provided uniform flow across the jets' width $(5 \mathrm{~mm})$ and length $(130 \mathrm{~mm})$. Nitrogen sheath flows with the same exit velocities as the reactive jets were employed on both sides of both reactant streams to prevent secondary flames. The jets were maintained at room temperature by water-cooling. The apparatus was enclosed in a ventilated box to suppress room draft influences. A schematic and photograph of the apparatus are given in Figure S1. Edge-flame propagation or retreat was recorded using high-speed video.

For conditions resulting in $\mathrm{U}_{\text {edge }}>0$, an $\mathrm{N}_{2}$ jet was used to extinguish or "erase" the flame starting at one end, then the jet was retracted, enabling the edge-flame to advance. For conditions resulting in $\mathrm{U}_{\text {edge }}<0$, 
first a mixture having $\mathrm{U}_{\text {edge }}>0$ was introduced, then electrically-heated wires at both slot ends were activated, then $\mathrm{X}_{\mathrm{o}}$ and $\mathrm{X}_{\mathrm{f}}$ were slowly reduced to the desired values. The heated wires provided localized flame temperature enhancement, thus locally increased reaction rates at the flame ends, anchoring these ends under conditions where they would retreat without localized heating. To induce extinction, the $\mathrm{N}_{2}$ jet was introduced to separating one flame end from its anchoring hot-wire, enabling observation of the retreating edge-flame. Video data were analyzed to infer $\mathrm{U}_{\text {edge. }}$ Because the slot-jet aspect ratio is finite there is a slight extensional flow along the slot length which slightly affects $\mathrm{U}_{\text {edge }}$ in the laboratory frame; as in prior work [10], this bias is nullified by interpolating $\mathrm{U}_{\text {edge }}$ vs. position along the slot to the jet centerline.

Table 1 shows the mixtures employed. The "baseline" case was $\mathrm{CH}_{4}-\mathrm{N}_{2}$ vs. $\mathrm{O}_{2}-\mathrm{N}_{2}$ which provides $\mathrm{Le}_{\mathrm{f}} \approx \mathrm{Le}_{\mathrm{o}} \approx 1 . \quad$ All $\mathrm{CH}_{4}-\mathrm{N}_{2} / \mathrm{O}_{2}-\mathrm{N}_{2}$ compositions were created so that stoichiometric combinations of fuel and oxidant streams result in $\mathrm{CH}_{4} / \mathrm{O}_{2} / \mathrm{N}_{2}=1 / 2 / 9.5$ (increasing $\mathrm{Z}_{\text {st }}$ corresponds to more of the $9.5 \mathrm{~N}_{2}$ from the $\mathrm{O}_{2}$ to $\mathrm{CH}_{4}$ stream), thus all stoichiometric combinations have the same premixed-flame properties, specifically unburned-to-burned gas density ratio $\left(\rho_{\mathrm{u}} / \rho_{\mathrm{b}}\right)$, adiabatic flame temperature $\left(\mathrm{T}_{\mathrm{f}}\right)$ and laminar burning velocity $\left(\mathrm{S}_{\mathrm{L}}\right) . \quad \mathrm{CH}_{4}-\mathrm{CO}_{2}$ vs. $\mathrm{O}_{2}-\mathrm{CO}_{2}$ mixtures were chosen to provide $\mathrm{Le}_{\mathrm{f}} \approx \mathrm{Le}_{\mathrm{o}}<1 . \mathrm{C}_{4} \mathrm{H}_{10}-\mathrm{N}_{2}$ vs. $\mathrm{O}_{2}-\mathrm{N}_{2}$ mixtures were chosen to have nearly the same $\mathrm{S}_{\mathrm{L}}$ as the $\mathrm{CH}_{4}-\mathrm{N}_{2}$ vs. $\mathrm{O}_{2}-\mathrm{N}_{2}$ mixtures with $\mathrm{Le}_{\mathrm{o}} \approx 1$ again but now $\mathrm{Le}_{\mathrm{f}}>1$. Both $\mathrm{n}-\mathrm{C}_{4} \mathrm{H}_{10}$ and $\mathrm{i}-\mathrm{C}_{4} \mathrm{H}_{10}$ were tested to assess possible effects of low-temperature chemistry, since $\mathrm{n}-\mathrm{C}_{4} \mathrm{H}_{10}$ decomposes more readily at low temperatures and thus has shorter ignition delays $[12,13] . \mathrm{C}_{4} \mathrm{H}_{10}-\mathrm{CO}_{2}$ vs. $\mathrm{O}_{2}-\mathrm{CO}_{2}$ mixtures were chosen to provide reactant Lewis numbers "straddling" unity $\left(\mathrm{Le}_{\mathrm{f}}>1\right.$ but $\left.\mathrm{Le}_{\mathrm{o}}<1\right)$. Finally $\mathrm{C}_{3} \mathrm{H}_{8}-\mathrm{N}_{2}$ vs. $\mathrm{O}_{2}-\mathrm{N}_{2}$ and $\mathrm{CH}_{3} \mathrm{OCH}_{3}-\mathrm{N}_{2}$ vs. $\mathrm{O}_{2}-\mathrm{N}_{2}$ mixtures with nearly the same $\mathrm{S}_{\mathrm{L}}$ as the other fuel- $\mathrm{O}_{2}-\mathrm{N}_{2}$ mixtures were compared since $\mathrm{C}_{3} \mathrm{H}_{8}$ and $\mathrm{CH}_{3} \mathrm{OCH}_{3}$ (dimethyl ether, DME) have nearly the same $\mathrm{Le}_{\mathrm{f}}$ but DME has much greater low-temperature reactivity since (unlike most hydrocarbons) DME does not inhibit its own oxidation; this is because the inhibiting reaction of oxygen with the fuel radical obtained from $\mathrm{H}$ atom abstraction cannot occur with DME [14].

Edge-flame theory [5-8] predicts that for adiabatic edge-flames with $\mathrm{Le}_{\mathrm{f}}=\mathrm{Le}_{\mathrm{o}}=1$, constant density and low $\sigma, \mathrm{U}_{\text {edge }} / \mathrm{S}_{\mathrm{L}}=1$. Moreover, effects of density variation on $\mathrm{U}_{\text {edge }}$ scales with $\left(\rho_{\mathrm{u}} / \rho_{\mathrm{b}}\right)^{1 / 2}[18]$. 
Consequently, we expect $\mathrm{U}_{\text {edge }} / \mathrm{S}_{\mathrm{L}}\left(\rho_{\mathrm{u}} / \rho_{\mathrm{b}}\right)^{1 / 2} \approx 1$ if Lewis number and heat loss influences are negligible, thus all $\mathrm{U}_{\text {edge }}$ data are scaled accordingly.

\begin{tabular}{cccccccc}
\hline Fuel & Diluent & Fuel / $\mathbf{O}_{2} /$ Diluent & $\mathbf{L e}_{\mathrm{f}}$ & $\mathbf{L e}_{\mathrm{o}}$ & $\boldsymbol{\rho}_{\mathrm{u}} / \boldsymbol{\rho}_{\mathrm{b}}$ & $\mathbf{T}_{\mathrm{f}}$ & $\mathbf{S}_{\mathbf{L}}(\mathbf{c m} / \mathbf{s})$ \\
\hline $\mathrm{CH}_{4}$ & $\mathrm{~N}_{2}$ & $1 / 2 / 9.5$ & 0.96 & 1.10 & 6.81 & 2024 & 21.3 \\
$\mathrm{CH}_{4}$ & $\mathrm{CO}_{2}$ & $1 / 2 / 7$ & 0.73 & 0.83 & 6.15 & 1828 & 5.19 \\
$\mathrm{isO}_{-} \mathrm{C}_{4} \mathrm{H}_{10}$ & $\mathrm{~N}_{2}$ & $1 / 6.5 / 30$ & 2.16 & 1.04 & 7.37 & 2100 & 20.4 \\
$\mathrm{n}_{-} \mathrm{C}_{4} \mathrm{H}_{10}$ & $\mathrm{~N}_{2}$ & $1 / 6.5 / 30$ & 2.16 & 1.04 & 7.40 & 2109 & 26.7 \\
iso- $_{4} \mathrm{H}_{10}$ & $\mathrm{CO}_{2}$ & $1 / 6.5 / 20$ & 1.73 & 0.77 & 7.06 & 1980 & 7.29 \\
$\mathrm{n}_{-} \mathrm{C}_{4} \mathrm{H}_{10}$ & $\mathrm{CO}_{2}$ & $1 / 6.5 / 20$ & 1.73 & 0.77 & 7.09 & 1987 & 11.0 \\
$\mathrm{C}_{3} \mathrm{H}_{8}$ & $\mathrm{~N}_{2}$ & $1 / 5 / 24.6$ & 1.86 & 1.05 & 7.10 & 2040 & 22.1 \\
$\mathrm{CH}_{3} \mathrm{OCH}_{3}$ & $\mathrm{~N}_{2}$ & $1 / 3 / 17$ & 1.81 & 1.02 & 6.87 & 1948 & 22.1 \\
\hline
\end{tabular}

Table 1. Properties of the mixtures tested. $S_{\mathrm{L}}$ was calculated using CHEMKIN [15] with USC Mech II kinetics [16], except for $\mathrm{CH}_{3} \mathrm{OCH}_{3}$ where [17] was used. [Two-column table.]

\section{Results and discussion}

\subsection{Experiments}

Figure 1 shows false-color direct images of typical edge-flames. In all cases the trailing regions are essentially flat and showed traditional non-premixed flame behavior. Fast-advancing edge-flames generally show some curvature near the leading edge (Fig. 1b) whereas retreating (Figs. 1a and 1c) and slowly advancing edges are generally nearly flat.

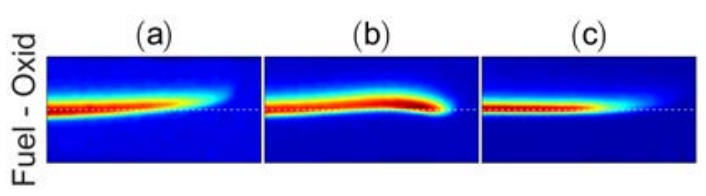

Figure 1. False-color images of direct emission from edge-flames in mixtures of i$\mathrm{C}_{4} \mathrm{H}_{10} / \mathrm{O}_{2} / \mathrm{CO}_{2}=1 / 5 / 20, \mathrm{Z}_{\mathrm{st}}=0.5$ : (a) $\sigma=14 / \mathrm{s}$, retreating from right to left; (b) $\sigma=20 / \mathrm{s}$, advancing from left to right; (c) $\sigma=43 / \mathrm{s}$, retreating from right to left. 
Figures $2 \mathrm{a}-\mathrm{h}$ show the effects of $\mathrm{Z}_{\text {st }}$ on the scaled edge-flame speed for each fuel $/ \mathrm{O}_{2} /$ diluent combination tested. Results are plotted for several fixed values of global strain rate $\sigma$ so the effect of $Z_{\text {st }}$ with all other experimental parameters held constant is readily seen. It should be noted that for each of these 8 plots, on each plot, every point corresponds to the same mixture (same ratio of fuel $/ \mathrm{O}_{2} / \mathrm{diluent}_{\text {, }}$ thus same $\rho_{u} / \rho_{b}, T_{f}$ and $\left.S_{I}\right)$ when fuel and $\mathrm{O}_{2}$ streams are combined in stoichiometric proportions, yet the resulting behavior varies drastically depending on $Z_{\text {st }}$ and $\sigma$.
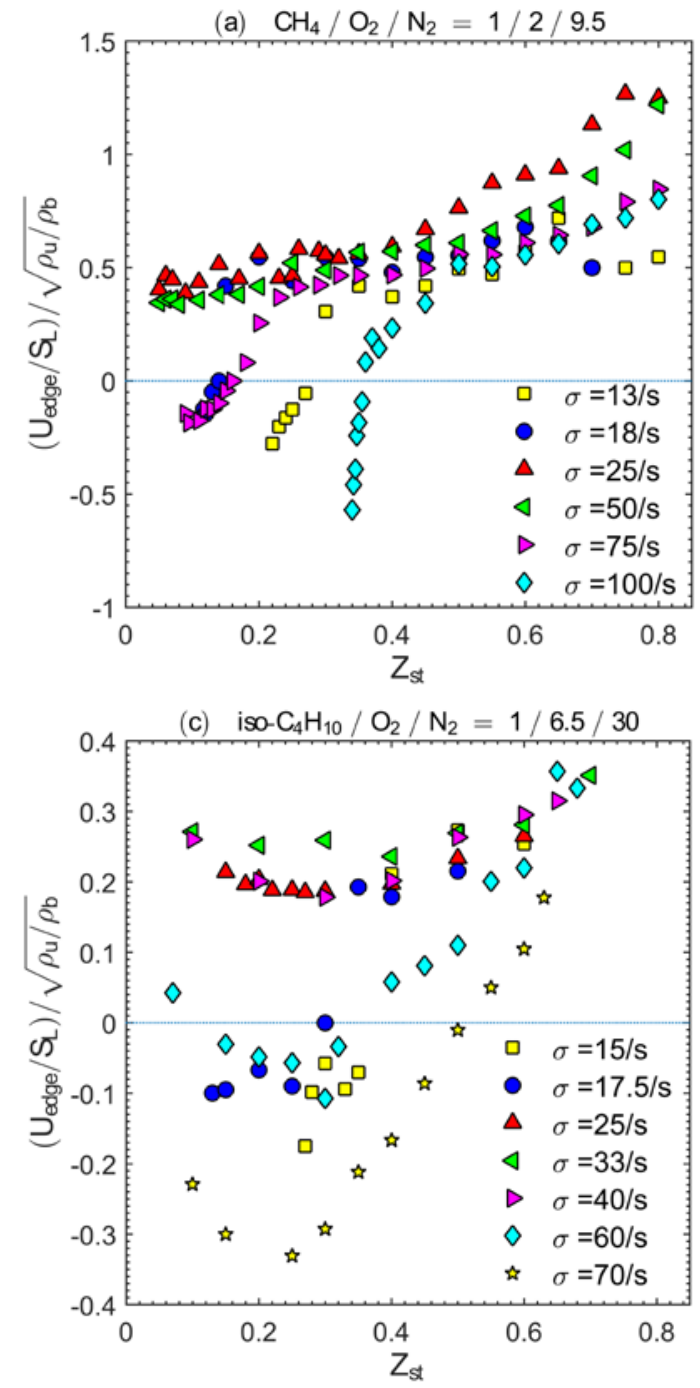

(b) $\mathrm{CH}_{4} / \mathrm{O}_{2} / \mathrm{CO}_{2}=1 / 2 / 7$
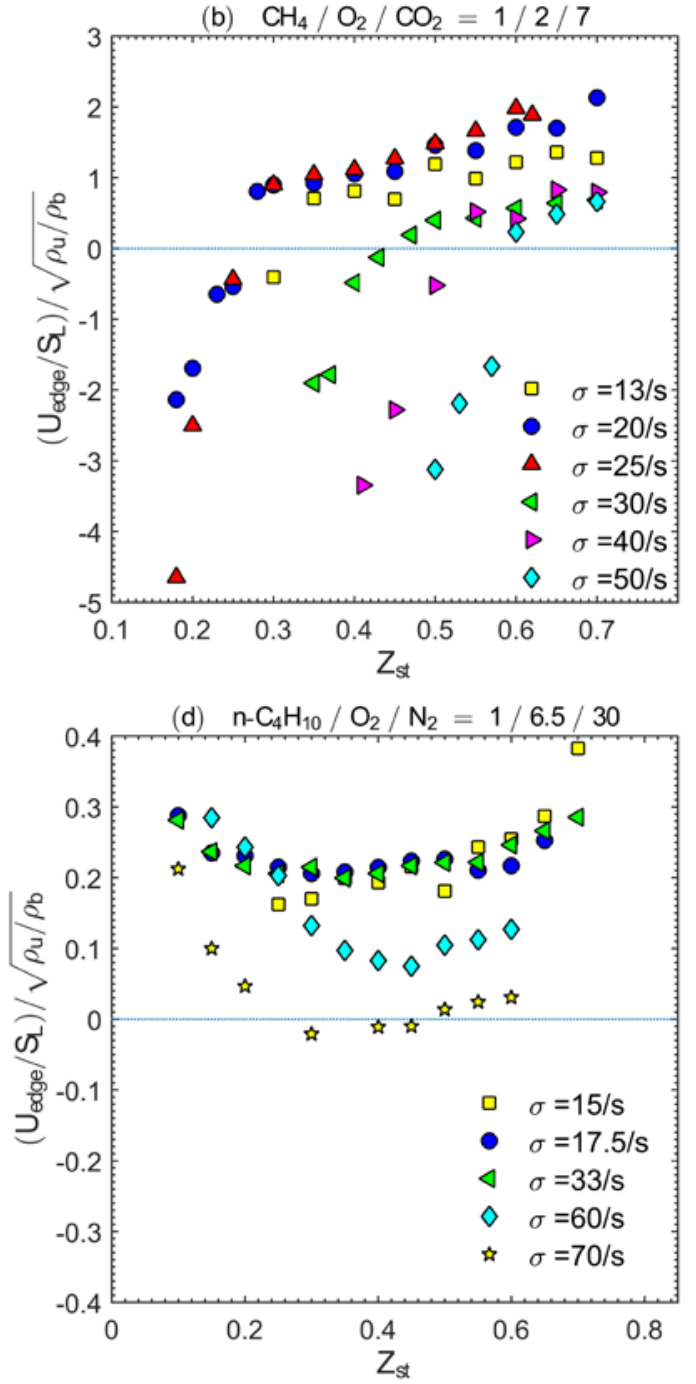

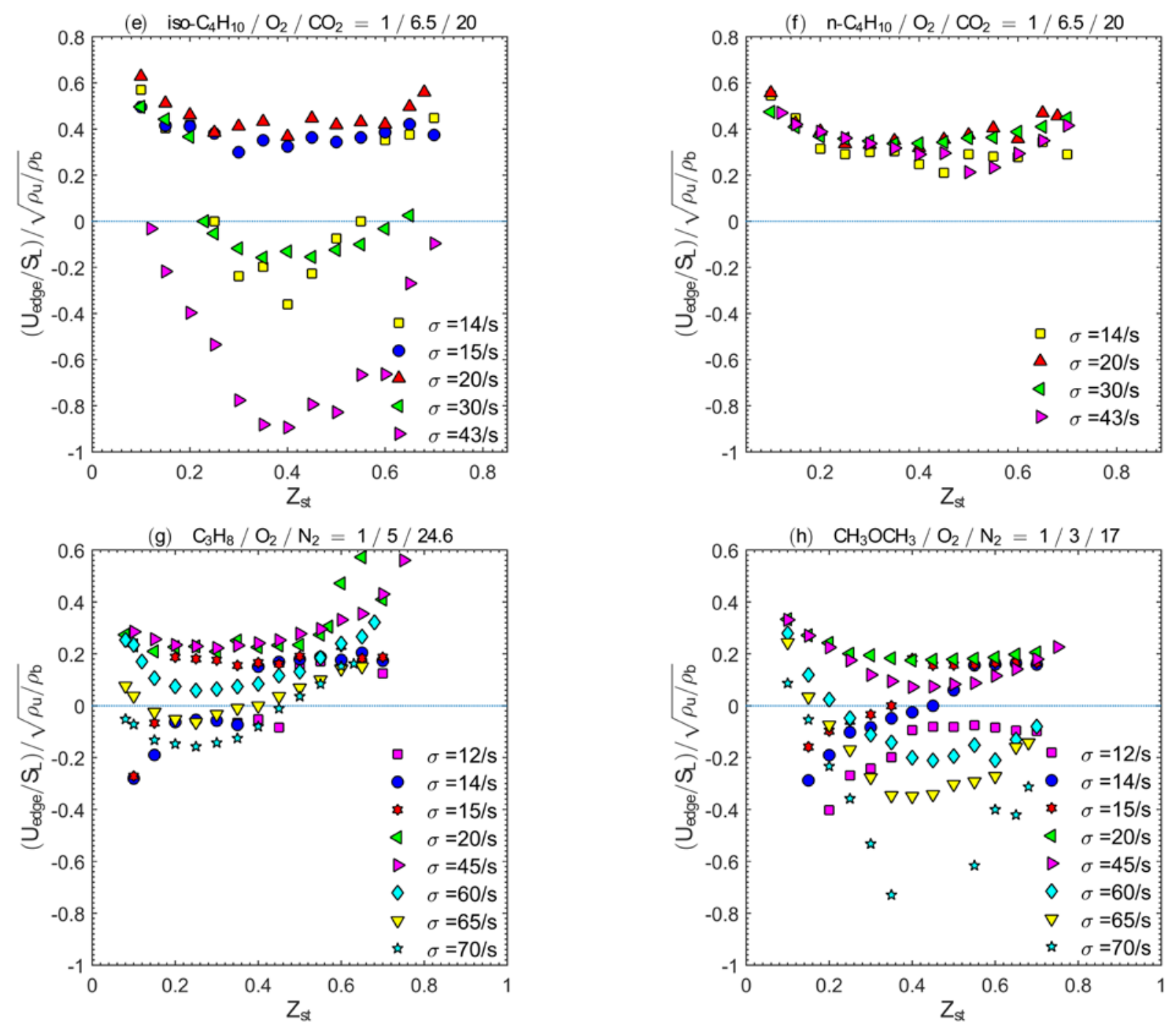

Figure 2. Effect of $Z_{\text {st }}$ on scaled edge-flame speeds for several fixed values of global strain rate $\sigma$.

For the baseline $\mathrm{CH}_{4}-\mathrm{N}_{2}$ vs. $\mathrm{O}_{2}-\mathrm{N}_{2}$ mixtures (Fig. 2a), several features are apparent. First, $\mathrm{U}_{\text {edge }}$ increases monotonically with $Z_{\text {st }}$ for all strain rates $(\sigma)$, rather than being symmetric with respect to $Z_{\text {st }}=0.5$. This is consistent with limited prior edge-flame data [10] as well as the effect of $Z_{\text {st }}$ on extinction strain rate $\left(\sigma_{\text {ext }}\right)$ of uniform nonpremixed counterflow flames [11]. The reasons for this chemical effect were discussed in the Introduction; a key question addressed in this work is whether this trend is universal. Second, as is well known from theory [8] and prior experiments [10], extinction limits $\left(\mathrm{U}_{\text {edge }} \rightarrow-\infty\right)$ exist at both high and low $\sigma$, due to insufficient residence time and heat losses, respectively. Third, even for fixed $\sigma$, $\mathrm{U}_{\text {edge }}$ can actually transition from positive to negative values to extinction as $Z_{\text {st }}$ is decreased. Fourth, for intermediate 
$\sigma$ (about 25/s - 50/s, away from both low- $\sigma$ and high- $\sigma$ extinction limits) there is almost no effect of $\sigma$ on $\mathrm{U}_{\text {edge. }}$ Finally, the scaled non-dimensional edge-flame speeds are significantly less than/greater than unity for small/large values of $Z_{\text {st }}$, indicating unexpectedly weak/strong flames depending on $Z_{\text {st. }}$.

The reported values of $\sigma$ may appear rather low, however, it should be noted that these are global strain rates based on cold-flow properties; the axial velocity gradient $\partial \mathrm{u} / \partial \mathrm{x}$ at the reaction zone are much larger due to thermal expansion effects. Computations (described below) show that, for example, for $\mathrm{CH}_{4-}$ $\mathrm{N}_{2}$ vs. $\mathrm{O}_{2}-\mathrm{N}_{2}$ mixtures with $\mathrm{Z}_{\mathrm{st}}=0.5$ and global $\sigma=96 / \mathrm{s}, \partial \mathrm{u} / \partial \mathrm{x}$ at $\mathrm{Z}=\mathrm{Z}_{\mathrm{st}}$ is $424 / \mathrm{s}$. Nevertheless, global properties are considered relevant because $\partial \mathrm{u} / \partial \mathrm{x}$ varies both in the streamwise and spanwise direction near the flame edge, thus no uniquely-definable local value of $\sigma$ exists for edge-flames. Moreover, correlations of strain effects on turbulent flames [19] typically employ global strain rate estimates based on the cold-flow conditions.

Figure $2 \mathrm{~b}$ shows that mixtures with $\mathrm{Le}_{\mathrm{f}} \approx \mathrm{Le}_{\mathrm{o}}<1$ show the same trends observed for the baseline $\mathrm{Le}_{\mathrm{f}} \approx \mathrm{Le}_{\mathrm{o}} \approx 1$ case, namely that $\mathrm{U}_{\text {edge }}$ increases monotonically with increasing $\mathrm{Z}_{\text {st }}$, i.e. the same chemical effect exists. The only substantive difference is that away from extinction limits the scaled non-dimensional edgeflame speeds can be much greater than in the $\mathrm{Le}_{\mathrm{f}} \approx \mathrm{Le}_{\mathrm{o}} \approx 1$ case; it is well established both theoretically [9] and experimentally [10] that $\mathrm{U}_{\text {edge }}$ increases substantially with decreasing Le.

Figure 2c shows that a larger hydrocarbon $\left(i-\mathrm{C}_{4} \mathrm{H}_{10}\right.$ ) having $\mathrm{Le}_{\mathrm{f}}>1$ (but still employing $\mathrm{O}_{2}-\mathrm{N}_{2}$ oxidizer so that $\mathrm{Le}_{\mathrm{o}} \approx 1$ ) exhibits drastically different behavior, specifically $\mathrm{U}_{\text {edge }} \mathrm{vs}$. $\mathrm{Z}_{\mathrm{st}}$ is non-monotonic $(\mathrm{U}$ shaped) with the lowest values at $Z_{\text {st }} \approx 0.3$; in fact, for some $\sigma, \mathrm{U}_{\text {edge }}$ is positive at high and low $Z_{\text {st }}$ yet negative at intermediate $Z_{\text {st. }}$ Seemingly the same chemical effect found for $\mathrm{CH}_{4}$ is present at high $\mathrm{Z}_{\text {st }}$ but some additional factor affects $U_{\text {edge }}$ at low $Z_{\text {st. }}$ All scaled values of $U_{\text {edge }}$ are much less than unity because of high $\mathrm{Le}_{\mathrm{f}}$. Again, both high- and low- $\sigma$ extinction limits exist.

To search for the cause of this unusual non-monotonic behavior, $\mathrm{U}_{\text {edge }}$ was measured for $\mathrm{n}-\mathrm{C}_{4} \mathrm{H}_{10}$ fuel (Fig. 2d) under conditions otherwise identical to i- $\mathrm{C}_{4} \mathrm{H}_{10}$ (Fig. 2c). This strategy assesses the effect of fuel structure, specifically low-temperature chemistry which is more prevalent in $\mathrm{n}-\mathrm{C}_{4} \mathrm{H}_{10}$. Figure $2 \mathrm{~d}$ shows 
that non-monotonic behavior is also observed with $\mathrm{n}-\mathrm{C}_{4} \mathrm{H}_{10}$. Away from low- $\sigma$ and high- $\sigma$ extinction limits, $\mathrm{U}_{\text {edge }}$ is nearly identical for $\mathrm{i}-\mathrm{C}_{4} \mathrm{H}_{10}$ and $\mathrm{n}-\mathrm{C}_{4} \mathrm{H}_{10}$, however, close to both limits $\mathrm{n}-\mathrm{C}_{4} \mathrm{H}_{10}$ has much higher $\mathrm{U}_{\text {edge. }}$ Consequently, low-temperature chemistry apparently affects $\mathrm{U}_{\text {edge }}$ near extinction limits, but is not the root cause of the non-monotonic trend.

To assess the relative roles of $\mathrm{Le}_{\mathrm{f}}$ and $\mathrm{Le}_{\mathrm{o}}, \mathrm{U}_{\text {edge }}$ was measured for $\mathrm{i}-\mathrm{C}_{4} \mathrm{H}_{10}-\mathrm{CO}_{2}$ and $\mathrm{n}-\mathrm{C}_{4} \mathrm{H}_{10}-\mathrm{CO}_{2}$ vs. $\mathrm{O}_{2}-\mathrm{CO}_{2}$ mixtures (Figs. 2e and 2f) for which $\mathrm{Le}_{\mathrm{f}}$ and $\mathrm{Le}_{\mathrm{o}}$ "straddle" unity. No significant qualitative difference from the comparison of $\mathrm{i}-\mathrm{C}_{4} \mathrm{H}_{10}-\mathrm{N}_{2}$ and $\mathrm{n}-\mathrm{C}_{4} \mathrm{H}_{10}-\mathrm{N}_{2}$ vs. $\mathrm{O}_{2}-\mathrm{N}_{2}$ mixtures were observed, although again scaled non-dimensional values of $\mathrm{U}_{\text {edge }}$ are much larger with $\mathrm{CO}_{2}$ dilution because of the lower Lewis numbers. For both $\mathrm{CH}_{4}$ and $\mathrm{C}_{4} \mathrm{H}_{10}$ fuels, $\mathrm{CO}_{2}$-diluted mixtures have scaled non-dimensional values of $\mathrm{U}_{\text {edge }}$ that are roughly twice that of $\mathrm{N}_{2}$-diluted mixtures.

One possible explanation for the non-monotonic behavior of $\mathrm{U}_{\text {edge }}$ is as follows. It is well known [20] that for strained counterflow flames near extinction with single-step chemistry, the more fully consumed reactant (that does not leak significantly through the reaction zone) is $\mathrm{O}_{2}$ for $\mathrm{Z}_{\text {st }}<0.5$ and fuel for $\mathrm{O}_{2}$ for $\mathrm{Z}_{\mathrm{st}}>0.5$. Prior work on diffusive-thermal instabilities of nonpremixed flames [21] showed that the effective Lewis number (for interpreting instability behavior) is that of the more fully consumed reactant. Consequently, for sufficiently low $Z_{\text {st }}$ the "effective" Le (Leeff) should be Le whereas for high $Z_{\text {st }}$ it should be $\mathrm{Le}_{\mathrm{f}}$. If $\mathrm{Le}_{\mathrm{f}} \approx \mathrm{Le}_{\mathrm{o}}$ then $\mathrm{Le}_{\text {eff }}$ would be the same for all $\mathrm{Z}_{\text {st }}$ and only the chemical effect (which causes $\mathrm{U}_{\text {edge }}$ to increase monotonically with $Z_{s t}$ ) would be present. However, for cases with $\operatorname{Le}_{\mathrm{f}}>\mathrm{Le}_{\mathrm{o}}, \mathrm{Le}_{\mathrm{eff}}$ would be lower $\left(\approx \mathrm{Le}_{\mathrm{o}}\right)$ at low $\mathrm{Z}_{\text {st }}$ and higher $\left(\approx \mathrm{Le}_{\mathrm{f}}\right)$ at high $\mathrm{Z}_{\mathrm{st}}$. The lower $\mathrm{Le}_{\text {eff }}$ at low $\mathrm{Z}_{\mathrm{st}}$ would in turn lead to higher $\mathrm{U}_{\text {edge }}$ than if Le $\mathrm{e}_{\text {eff }}$ were constant. This explanation of the combined chemical + Lewis number effects is entirely consistent with the observed monotonic behavior of $\mathrm{U}_{\text {edge }}$ for $\mathrm{Le}_{\mathrm{f}} \approx \mathrm{Le}_{\mathrm{o}}$ and $\mathrm{U}$-shaped behavior for $\mathrm{Le}_{\mathrm{f}}>\mathrm{Le}_{\mathrm{o}}$, however, Seshadri and Bui [22] showed that hydrocarbon-oxygen oxidation in nonpremixed flames does not behave according to this simple single-step reaction model; in fact, $\mathrm{O}_{2}$ is the leaking reactant for all $\mathrm{Z}_{\mathrm{st}}$ because hydrocarbon decomposition by radicals is much more rapid than $\mathrm{O}_{2}$ decomposition. 
Nevertheless, fuel will survive part-way to the radical production zone and thus $\mathrm{Le}_{\mathrm{f}}$ may be expected to have some effect on $\mathrm{Le}_{\text {eff }}$ and thus $\mathrm{U}_{\text {edge }}$.

To assess the effect of fuel decomposition rates, DME is appropriate because of its significant lowtemperature reactivity compared to hydrocarbons (see Introduction.) For comparison with hydrocarbons, propane was selected because its $\mathrm{Le}_{\mathrm{f}}$ is very similar to DME. As might be expected, $\mathrm{C}_{3} \mathrm{H}_{8}-\mathrm{N}_{2}$ vs. $\mathrm{O}_{2}-\mathrm{N}_{2}$ mixtures (Fig. 2g) show behavior very similar to i- $\mathrm{C}_{4} \mathrm{H}_{10}-\mathrm{N}_{2}$ vs. $\mathrm{O}_{2}-\mathrm{N}_{2}$ mixtures (Fig. 2c) but with slightly higher values of $\mathrm{U}_{\text {edge }}$ due to the slightly lower $\mathrm{Le}_{\mathrm{f}}$ of $\mathrm{C}_{3} \mathrm{H}_{8}$. In contrast, $\mathrm{CH}_{3} \mathrm{OCH}_{3}-\mathrm{N}_{2}$ vs. $\mathrm{O}_{2}-\mathrm{N}_{2}$ mixtures (Fig. 2h) show higher values of $\mathrm{U}_{\text {edge }}$ than $\mathrm{C}_{3} \mathrm{H}_{8}-\mathrm{N}_{2}$ vs. $\mathrm{O}_{2}-\mathrm{N}_{2}$ mixtures (Fig. $2 \mathrm{~g}$ ) at low $\mathrm{Z}_{\text {st }}$ but lower values of $\mathrm{U}_{\text {edge }}$ at high $\mathrm{Z}_{\mathrm{st}}$.

\subsection{Computations}

In order to interpret these data, rather than attempting brute-force calculations of multidimensional edge-flames, we attempted to identify (if possible) an easily-determined 1D flame parameter characterizing the effects of $Z_{s t}$. The premixed laminar burning velocity $\left(\mathrm{S}_{\mathrm{L}}\right)$ of the stoichiometric mixture of fuel and oxidant streams is clearly inappropriate since for each plot (Figs. 2a-h), $\mathrm{S}_{\mathrm{L}}$ is the same for every point. In contrast, the adiabatic extinction strain rate $\left(\sigma_{\text {ext }}\right)$ is known [11] to depend on $Z_{\text {st }}$ in a manner similar to the observed effect of $Z_{\text {st }}$ on $\mathrm{U}_{\text {edge, }}$, at least for $\mathrm{CH}_{4}-\mathrm{N}_{2}$ vs. $\mathrm{O}_{2}-\mathrm{N}_{2}$ mixtures. With this motivation $\sigma_{\text {ext }}$ vs. $Z_{\text {st }}$ in a 1D counterflow was computed for all mixtures studied experimentally, using the same jet exit velocities and jet spacings as the experiments. Figure 3 shows the computed (using the same code and kinetic data used to obtain $S_{L}$ in Table 1) effect of $Z_{s t}$ on the high- $\sigma$ extinction strain rate $\left(\sigma_{\text {ext }}\right)$ Qualitatively, computed values of $\sigma_{\text {ext }}$ show trends with $Z_{\text {st }}$ remarkably similar to the measured effects of $Z_{\text {st }}$ on $U_{\text {edge }}$ for $\sigma$ not close to either the high- $\sigma$ or low- $\sigma$ extinction limits. Specifically both the experimental $\mathrm{U}_{\text {edge }}$ and computed $\sigma_{\text {ext }}$ : (1) increase monotonically with $\mathrm{Z}_{\text {st }}$ for $\mathrm{CH}_{4}-\mathrm{O}_{2}$-diluent mixtures; (2) exhibit $\mathrm{U}$-shaped trends with minima at $\mathrm{Z}_{\text {st }} \approx 0.3-0.4$ for all $\mathrm{C}_{3} \mathrm{H}_{8}$ and $\mathrm{C}_{4} \mathrm{H}_{10}$ cases; (3) are higher for all $\mathrm{n}-\mathrm{C}_{4} \mathrm{H}_{10}$ than i- $\mathrm{C}_{4} \mathrm{H}_{10}$ cases; and (4) are higher for $\mathrm{CH}_{3} \mathrm{OCH}_{3}$ than $\mathrm{C}_{3} \mathrm{H}_{8}$ at low $\mathrm{Z}_{\text {st }}$ with the opposite behavior at high $\mathrm{Z}_{\text {st. }}$ Table 2 shows quantitative 
comparisons of $\sigma_{\text {ext }}$ inferred from experimental data (where $\mathrm{U}_{\text {edge }} \rightarrow-\infty$ ) to predictions (Fig. 3). The ratio of experimental to computed values of $\sigma_{\text {ext }}$ are on average 0.91 with a standard deviation of 0.15 . No adjustments to either model or experiment were made to obtain this agreement. These qualitative and quantitative comparisons strongly suggest that $\sigma_{\text {ext }}$ is a suitable $1 \mathrm{D}$ property for interpreting the behavior of multi-dimensional edge-flame structures.
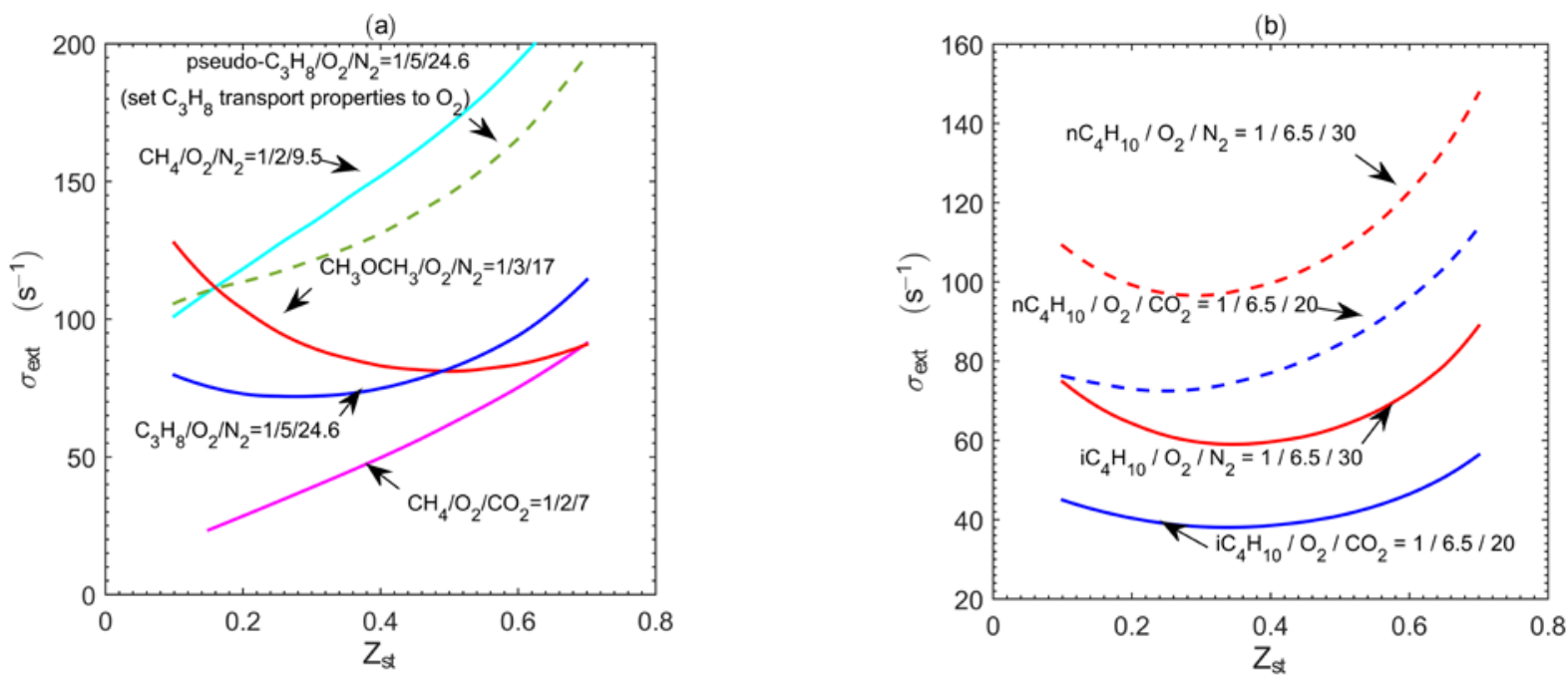

Figure 3. Computed effect of $\mathrm{Z}_{\text {st }}$ on extinction strain rates in $1 \mathrm{D}$ counterflows for all mixtures tested (Table 1). (a) $\mathrm{CH}_{4}, \mathrm{C}_{3} \mathrm{H}_{8}$ and $\mathrm{CH}_{3} \mathrm{OCH}_{3}$ mixtures; (b) $\mathrm{n}-\mathrm{C}_{4} \mathrm{H}_{10}$ and $\mathrm{i}-\mathrm{C}_{4} \mathrm{H}_{10}$ mixtures.

\begin{tabular}{cccc}
\hline Mixture & $\mathbf{Z}_{\text {st }}$ & $\begin{array}{c}\sigma_{\text {ext }} \\
(\mathbf{e x p})\end{array}$ & $\begin{array}{c}\sigma_{\text {ext }} \\
(\mathbf{c o m p})\end{array}$ \\
\hline $\mathrm{CH}_{4} / \mathrm{O}_{2} / \mathrm{N}_{2}$ & 0.08 & 75 & 98 \\
& 0.32 & 100 & 137 \\
& & & \\
$\mathrm{CH}_{4} / \mathrm{O}_{2} / \mathrm{CO}_{2}$ & 0.18 & 25 & 27 \\
& 0.40 & 40 & 49 \\
& 0.50 & 50 & 61 \\
$\mathrm{i}-\mathrm{C}_{4} \mathrm{H}_{10} / \mathrm{O}_{2} / \mathrm{N}_{2}$ & 0.20 & 70 & 64 \\
& & & \\
$\mathrm{i}-\mathrm{C}_{4} \mathrm{H}_{10} / \mathrm{O}_{2} / \mathrm{CO}_{2}$ & 0.40 & 45 & 38 \\
& & & \\
$\mathrm{C}_{3} \mathrm{H}_{8} / \mathrm{O}_{2} / \mathrm{N}_{2}$ & 0.25 & 75 & 71 \\
$\mathrm{CH}_{3} \mathrm{OCH}_{3} / \mathrm{O}_{2} / \mathrm{N}_{2}$ & 0.35 & 70 & 85 \\
& 0.55 & 70 & 80 \\
\hline
\end{tabular}

Table 2. Comparisons of measured and computed extinction strain rates (units s ${ }^{-1}$ ). [Single-column table] 
With this motivation, numerical experiments were performed in which the reactant transport properties were modified from their real values to assess Lewis number effects. Figure $3 a$ shows that for $\mathrm{C}_{3} \mathrm{H}_{8}-\mathrm{O}_{2}-\mathrm{N}_{2}$ mixtures, artificially setting the Lennard-Jones parameters of $\mathrm{C}_{3} \mathrm{H}_{8}$ equal to those of $\mathrm{O}_{2}$ (effectively forcing $\mathrm{Le}_{\mathrm{f}} \approx \mathrm{Le}_{\mathrm{o}} \approx 1$ as with $\mathrm{CH}_{4}-\mathrm{O}_{2}-\mathrm{N}_{2}$ mixtures) caused $\sigma_{\text {ext }}$ values (dashed curve) to become monotonic with $\mathrm{Z}_{\text {st }}$ and quantitatively very similar to $\mathrm{CH}_{4}-\mathrm{O}_{2}-\mathrm{N}_{2}$ mixtures. Consequently, the nonmonotonic (U-shaped) behavior of $\mathrm{U}_{\text {edge }}$ vs. $\mathrm{Z}_{\mathrm{st}}$ for the higher hydrocarbons is very likely a result of Lewis number rather than chemical effects, whereas the unusual behavior of DME at low $Z_{\text {st }}$ is clearly related to the contrasting (compared to hydrocarbons) behavior of its well-known [14] low-temperature chemistry.

\section{Conclusions}

This work investigated the effect of stoichiometric mixture fraction $\left(Z_{\mathrm{st}}\right)$ on the propagation speeds of nonpremixed edge-flames $\left(\mathrm{U}_{\text {edge }}\right)$ in a variety of strategically-chosen hydrocarbon-diluent vs. $\mathrm{O}_{2}$-diluent combinations, with the intent of examining systematically the effects of transport and chemical effects, specifically Lewis numbers and high-temperature vs. low-temperature chemistry. Interpretation of results was facilitated by the use of values of fuel and oxidizer mass fractions such that, for a given fuel and diluent type, all stoichiometric combinations of the fuel and oxidizer streams result in the same mixture (thus same adiabatic flame temperature, density ratio and premixed laminar burning velocity) even though $Z_{\text {st }}$ varies widely depending on how the diluent is distributed between these streams.

With this approach to varying $Z_{\text {st }}$ it could be expected that $\mathrm{U}_{\text {edge }}$ would be constant since all values of $\mathrm{Z}_{\text {st }}$ result in the same fuel: $\mathrm{O}_{2}$ : diluent mixture, but clearly $\mathrm{U}_{\text {edge }}$ is far from constant as $\mathrm{Z}_{\mathrm{st}}$ is varied. At the second level, it could be expected that $\mathrm{U}_{\text {edge }}$ would be symmetric with respect to $Z_{\mathrm{st}}=0.5$, but again this is not the case even when fuel and oxidant have similar Lewis numbers, due to the previously-documented asymmetry of fuel vs. $\mathrm{O}_{2}$ decomposition in counterflow nonpremixed flames [11]. At the third level, it could be expected that $\mathrm{U}_{\text {edge }}$ would be the same for fuels with similar Le, but even this is not the case due to low-temperature chemistry effects (propane vs. DME, n-butane vs. iso-butane). As a result of the 
interactions of Lewis number and chemistry effects, $\mathrm{U}_{\text {edge }}$ may increase or decrease with increasing $Z_{\text {st }}$, or have a non-monotonic (U-shaped) behavior. Despite these potentially complicated interactions, it was found that all observed $U_{\text {edge }}$ vs. $Z_{\text {st }}$ trends are consistent with computed values of extinction strain rate $\left(\sigma_{\text {ext }}\right)$ of these mixtures in a $1 \mathrm{D}$ counterflow, thus $\sigma_{\text {ext }}$ serves as a simple surrogate for predicting edge-flame behavior.

These results indicate that the behavior of highly turbulent nonpremixed flames near extinction (where edge-flames develop [23]) depends critically on (1) fuel type (through Lewis number and chemical

effects), (2) degree of dilution of both fuel and oxidizer (characterized by $Z_{\text {st }}$, and (3) strain rate. This work provides some insight on the combined effects of these factors.

\section{Acknowledgments}

The authors are grateful to Prof. K. Seshadri for helpful discussions. This work was supported by the U.S. National Science Foundation, grant CBET-1236892.

\section{References}

[1] Williams F.A., Combustion Theory, $2^{\text {nd }}$ Ed., Westview Press, Boulder, CO, 1985.

[2] J.D. Buckmaster, Prog. Energy Combust. Sci. 28 (2002) 435-475.

[3] T.G. Vedarajan, J.D. Buckmaster, Combust. Flame, 114 (1998) 267-273.

[4] T.G. Vedarajan, J.D. Buckmaster, P.D. Ronney, Proc. Combust. Inst. 27 (1998) 537-544.

[5] J. Daou, A. Liñán, Combust. Flame 118 (1999) 479-488.

[6] J.D. Buckmaster, Combust. Sci. Tech 115 (1996) 41-68.

[7] J. Daou, A. Liñán, Combust. Theory Model. 2 (1998) 449-447.

[8] R. Daou, J. Daou, J. Dold, Proc. Combust. Inst. 29 (2002) 1559-1564.

[9] R. Daou, J. Daou, J. Dold. Combust. Theory Model. 8 (2004) 683-699.

[10] M.S. Cha, P.D. Ronney, Combust. Flame 146 (2006) 312-328. 
[11] R. Chen, R.L. Axelbaum, Combust. Flame 142 (2005) 62-71.

[12] S. Gersen, A.V. Mokhov, J.H. Darmeveil, H.B. Levinsky, Combust. Flame 157 (2010) 240-245.

[13] D. Healy, N.S. Donato, C.J. Aul, E.L. Petersen, C. M. Zinner, G. Bourque, H. J. Curran, Combust. Flame 157 (2010) 1540-1551.

[14] A. Rodriguez, O. Frottier, O. Herbinet, R. Fournet, R. Bounaceur, C. Fittschen, F. Battin-Leclerc, J. Phys. Chem A 119 (2015) 7905-7923.

[15] CHEMKIN 15131, Reaction Design: San Diego, 2013.

[16] H. Wang, X. You, A.V. Joshi, S.G. Davis, A. Laskin, F. Egolfopoulos, C.K. Law, USC Mech Version II. http://ignis.usc.edu/USC_Mech_II.htm (2007).

[17] S.L. Fischer, F.L. Dryer, H.J. Curran, Int. J. Chem. Kinet. 32 (2000) 713-740.

[18] R. Ruetsch, L. Vervisch, A. Liñán, Phys. Fluids 7 (1995) 1447-1454.

[19] D. Bradley, Proc. Combust. Inst. 24 (1992) 247-262.

[20] Liñán, A., Acta Astronaut. 1 (1974) 1007-1039.

[21] R. H. Chen, G. B. Mitchell, P. D. Ronney, Proc. Combust. Inst. 24 (1992) 213-221.

[22] K. Seshadri, X.S. Bai, Proc. Combust. Inst. 31 (2007) 1181-1188.

[23] A. Bhagatwala, E.R. Hawkes, J.H. Chen, "Dynamics of extinction and reignition in turbulent DME jet flames," 9 $9^{\text {th }}$ U.S. National Combustion Meeting, Cincinnati, OH, May 2015. 
Tables:

\begin{tabular}{cccccccc}
\hline Fuel & Diluent & Fuel / $\mathbf{O}_{2} /$ Diluent & $\mathbf{L e}_{\mathrm{f}}$ & $\mathbf{L e}_{\mathbf{o}}$ & $\boldsymbol{\rho}_{\mathrm{u}} / \boldsymbol{\rho}_{\mathrm{b}}$ & $\mathbf{T}_{\mathrm{f}}$ & $\mathbf{S}_{\mathbf{L}}(\mathbf{c m} / \mathbf{s})$ \\
\hline $\mathrm{CH}_{4}$ & $\mathrm{~N}_{2}$ & $1 / 2 / 9.5$ & 0.96 & 1.10 & 6.81 & 2024 & 21.3 \\
$\mathrm{CH}_{4}$ & $\mathrm{CO}_{2}$ & $1 / 2 / 7$ & 0.73 & 0.83 & 6.15 & 1828 & 5.19 \\
iso- $_{4} \mathrm{H}_{10}$ & $\mathrm{~N}_{2}$ & $1 / 6.5 / 30$ & 2.16 & 1.04 & 7.37 & 2100 & 20.4 \\
$\mathrm{n}_{-} \mathrm{C}_{4} \mathrm{H}_{10}$ & $\mathrm{~N}_{2}$ & $1 / 6.5 / 30$ & 2.16 & 1.04 & 7.40 & 2109 & 26.7 \\
iso- $_{4} \mathrm{H}_{10}$ & $\mathrm{CO}_{2}$ & $1 / 6.5 / 20$ & 1.73 & 0.77 & 7.06 & 1980 & 7.29 \\
$\mathrm{n}_{-} \mathrm{C}_{4} \mathrm{H}_{10}$ & $\mathrm{CO}_{2}$ & $1 / 6.5 / 20$ & 1.73 & 0.77 & 7.09 & 1987 & 11.0 \\
$\mathrm{C}_{3} \mathrm{H}_{8}$ & $\mathrm{~N}_{2}$ & $1 / 5 / 24.6$ & 1.86 & 1.05 & 7.10 & 2040 & 22.1 \\
$\mathrm{CH}_{3} \mathrm{OCH}_{3}$ & $\mathrm{~N}_{2}$ & $1 / 3 / 17$ & 1.81 & 1.02 & 6.87 & 1948 & 22.1 \\
\hline
\end{tabular}

Table 1. Properties of the mixtures tested. $S_{\mathrm{L}}$ was calculated using CHEMKIN [15] with USC Mech II kinetics [16], except for $\mathrm{CH}_{3} \mathrm{OCH}_{3}$ where [17] was used. [Two-column table.]

\begin{tabular}{cccc}
\hline Mixture & $\mathbf{Z}_{\text {st }}$ & $\begin{array}{c}\sigma_{\text {ext }} \\
(\mathbf{e x p})\end{array}$ & $\begin{array}{c}\boldsymbol{\sigma}_{\text {ext }} \\
(\mathbf{c o m p})\end{array}$ \\
\hline $\mathrm{CH}_{4} / \mathrm{O}_{2} / \mathrm{N}_{2}$ & 0.08 & 75 & 98 \\
& 0.32 & 100 & 137 \\
& & & \\
$\mathrm{CH}_{4} / \mathrm{O}_{2} / \mathrm{CO}_{2}$ & 0.18 & 25 & 27 \\
& 0.40 & 40 & 49 \\
& 0.50 & 50 & 61 \\
$\mathrm{i}-\mathrm{C}_{4} \mathrm{H}_{10} / \mathrm{O}_{2} / \mathrm{N}_{2}$ & 0.20 & 70 & 64 \\
& & & \\
$\mathrm{i}-\mathrm{C}_{4} \mathrm{H}_{10} / \mathrm{O}_{2} / \mathrm{CO}_{2}$ & 0.40 & 45 & 38 \\
& & & \\
$\mathrm{C}_{3} \mathrm{H}_{8} / \mathrm{O}_{2} / \mathrm{N}_{2}$ & 0.25 & 75 & 71 \\
$\mathrm{CH}_{3} \mathrm{OCH}_{3} / \mathrm{O}_{2} / \mathrm{N}_{2}$ & 0.35 & 70 & 85 \\
& 0.55 & 70 & 80 \\
\hline
\end{tabular}

Table 2. Comparisons of measured and computed extinction strain rates (units s $\mathrm{s}^{-1}$ ). [Single-column table] 


\section{List of Figure Captions:}

- Figure 1. False-color images of direct emission from edge-flames in mixtures of i$\mathrm{C}_{4} \mathrm{H}_{10} / \mathrm{O}_{2} / \mathrm{CO}_{2}=1 / 5 / 20, \mathrm{Z}_{\mathrm{st}}=0.5$ : (a) $\sigma=14 / \mathrm{s}$, retreating from right to left; (b) $\sigma=20 / \mathrm{s}$, advancing from left to right; (c) $\sigma=43 / \mathrm{s}$, retreating from right to left.

- Figure 2. Effect of $Z_{\text {st }}$ on scaled edge-flame speeds for several fixed values of global strain rate $\sigma$.

- Figure 3. Computed effect of Zst on extinction strain rates in 1D counterflows for all mixtures tested (Table1). (a) $\mathrm{CH} 4, \mathrm{C} 3 \mathrm{H} 8$ and $\mathrm{CH} 3 \mathrm{OCH} 3$ mixtures; (b) n-C4H10 and i-C4H10 mixtures. 
Tables:

\begin{tabular}{cccccccc}
\hline Fuel & Diluent & Fuel / $\mathbf{O}_{2} /$ Diluent & $\mathbf{L e}_{\mathrm{f}}$ & $\mathbf{L e}_{\mathrm{o}}$ & $\boldsymbol{\rho}_{\mathrm{u}} / \boldsymbol{\rho}_{\mathrm{b}}$ & $\mathbf{T}_{\mathrm{f}}$ & $\mathbf{S}_{\mathrm{L}}(\mathbf{c m} / \mathbf{s})$ \\
\hline $\mathrm{CH}_{4}$ & $\mathrm{~N}_{2}$ & $1 / 2 / 9.5$ & 0.96 & 1.10 & 6.81 & 2024 & 21.3 \\
$\mathrm{CH}_{4}$ & $\mathrm{CO}_{2}$ & $1 / 2 / 7$ & 0.73 & 0.83 & 6.15 & 1828 & 5.19 \\
iso- $_{4} \mathrm{H}_{10}$ & $\mathrm{~N}_{2}$ & $1 / 6.5 / 30$ & 2.16 & 1.04 & 7.37 & 2100 & 20.4 \\
$\mathrm{n}_{-} \mathrm{C}_{4} \mathrm{H}_{10}$ & $\mathrm{~N}_{2}$ & $1 / 6.5 / 30$ & 2.16 & 1.04 & 7.40 & 2109 & 26.7 \\
iso- $_{4} \mathrm{H}_{10}$ & $\mathrm{CO}_{2}$ & $1 / 6.5 / 20$ & 1.73 & 0.77 & 7.06 & 1980 & 7.29 \\
$\mathrm{n}_{-} \mathrm{C}_{4} \mathrm{H}_{10}$ & $\mathrm{CO}_{2}$ & $1 / 6.5 / 20$ & 1.73 & 0.77 & 7.09 & 1987 & 11.0 \\
$\mathrm{C}_{3} \mathrm{H}_{8}$ & $\mathrm{~N}_{2}$ & $1 / 5 / 24.6$ & 1.86 & 1.05 & 7.10 & 2040 & 22.1 \\
$\mathrm{CH}_{3} \mathrm{OCH}$ & $\mathrm{N}_{2}$ & $1 / 3 / 17$ & 1.81 & 1.02 & 6.87 & 1948 & 22.1 \\
\hline
\end{tabular}

Table 1. Properties of the mixtures tested. $S_{\mathrm{L}}$ was calculated using CHEMKIN [15] with USC Mech II kinetics [16], except for $\mathrm{CH}_{3} \mathrm{OCH}_{3}$ where [17] was used. [Two-column table.]

\begin{tabular}{cccc}
\hline Mixture & $\mathbf{Z}_{\text {st }}$ & $\begin{array}{c}\sigma_{\text {ext }} \\
(\text { exp) }\end{array}$ & $\begin{array}{c}\sigma_{\text {ext }} \\
\text { (comp) }\end{array}$ \\
\hline $\mathrm{CH}_{4} / \mathrm{O}_{2} / \mathrm{N}_{2}$ & 0.08 & 75 & 98 \\
& 0.32 & 100 & 137 \\
& & & \\
$\mathrm{CH}_{4} / \mathrm{O}_{2} / \mathrm{CO}_{2}$ & 0.18 & 25 & 27 \\
& 0.40 & 40 & 49 \\
& 0.50 & 50 & 61 \\
& & & \\
$\mathrm{i}-\mathrm{C}_{4} \mathrm{H}_{10} / \mathrm{O}_{2} / \mathrm{N}_{2}$ & 0.20 & 70 & 64 \\
& & & \\
$\mathrm{i}-\mathrm{C}_{4} \mathrm{H}_{10} / \mathrm{O}_{2} / \mathrm{CO}_{2}$ & 0.40 & 45 & 38 \\
& & & \\
$\mathrm{C}_{3} \mathrm{H}_{8} / \mathrm{O}_{2} / \mathrm{N}_{2}$ & 0.25 & 75 & 71 \\
& & & \\
$\mathrm{CH}_{3} \mathrm{OCH}_{3} / \mathrm{O}_{2} / \mathrm{N}_{2}$ & 0.35 & 70 & 85 \\
& 0.55 & 70 & 80 \\
\hline
\end{tabular}

Table 2. Comparisons of measured and computed extinction strain rates (units s ${ }^{-1}$ ). [Single-column table] 